\title{
Medical Plus Shaped Antenna for S, C, X and Ku Band Applications
}

\author{
Penchala Reddy Sura ${ }^{*}$, Sanam Narayana Reddy ${ }^{2}$ \\ ${ }^{1}$ Department of Electronics \& Communication Engineering, Visvodaya Engineering College, Kavali, AP, India \\ ${ }^{2}$ Department of Electronics \& Communication Engineering, Sri Venkateswara University, Tirupathi, AP, India
}

Corresponding Author Email: sura.440@gmail.com

https://doi.org/10.18280/i2m.180203

Received: 3 January 2019

Accepted: 11 March 2019

\section{Keywords:}

Ku-Band, multi-band operation, radiating patch, return loss, triple band

\begin{abstract}
In present days multiband operation of an antenna performs an inspiring role in wireless communication. In this paper, a Medical plus shaped antenna is proposed for $\mathrm{S}, \mathrm{C}, \mathrm{X}$ and $\mathrm{Ku}$ Band Applications and analyzed. The intended antenna constitutes a medical plus shaped radiating patch on the cost effective FR4-substrate having a thickness of about $1.6 \mathrm{~mm}$. A feed line of $50 \mathrm{ohms}$ is used to feed this antenna. Here a preferable impendence matching is attained by truncating a portion of the ground surface. The intended antenna has the potential to operate between the frequency range of $2.79 \mathrm{GHz}$ to $5.61 \mathrm{GHz}, 6.88 \mathrm{GHz}$ to $8.69 \mathrm{GHz}$ and $11.43 \mathrm{GHz}$ to $14.34 \mathrm{GHz}$ with $\mathrm{S}_{11}$ below $-10 \mathrm{~dB}$. The design of the antenna and its behavior over various frequencies ranges is done with the use of HFSS. The proposed antenna has higher gains at three bands. The simulated antenna is also fabricated and a fine agreement is attained in between simulated and measured parameters.
\end{abstract}

\section{INTRODUCTION}

The huge breakthroughs in communication systems accelerate the stipulation for small, low cost and effortless fabrication of antennas. So in order to attain the needs of the present day, the patch antennas came into the scene. The Patch antennas grab the interest of the present day investigators due to its inherent characters like less weight, reasonable price and flexibility in manufacturing and usage in hand held devices. Generally these patch antennas are metallic plates erected on any type of dielectric material [1].

The necessity for small compact and hand held devices leads to a headway in the design and development of multiband antennas. From its debut itself multiband antennas get hold of a very prominent position in modern days wireless communication systems. Multiband antennas minimize the use of more antennas in any device and there by shrinks the size of the device. The multiband antennas amalgamate various applications on a single antenna. Especially, stipulation for antennas adopted in WiMAX, WLAN and space communications pick up huge interest in the last twenty years [2-3].

A metamaterial based try-band antenna made of two cells consisting of L-shaped dumbbell unit with uncompleted ground surface is designed to operate at Wi-Max and WLAN appliances [4]. A multi-band antenna is developed by cutting slots of $U$ and $L$ patterns in the radiating patch for ITURegion1, WLAN and WiMAX applications [5]. A multi-band antenna is designed by making different slots in the radiating patch to operate at Wi-Max, C and X-bands applications [6]. A monopole antenna made up of rectangular radiating patch with chamfered edges and partial ground metal with $\mathrm{V}$-slot is developed to operate at UWB, Bluetooth, $\mathrm{X}$ and $\mathrm{Ku}$-band applications [7]. A radiating patch is slotted with $\mathrm{T}$-shape to design an antenna operating at $\mathrm{C}, \mathrm{X}$ and $\mathrm{Ku}$-bands [8]. A radiating patch inserted with rectangular feed is developed to function at the $\mathrm{C}$ - and $\mathrm{X}$-bands [9]. The technique of parasitic elements and phase difference approach is used to design the try band antenna array to a C, X and Ku bands [10].

The projected antenna consists of medical plus shaped radiating patch on a cost effective FR4-substrate to operate at three different bands. The $1^{\text {st }}$ one covers the WLAN, Wi-Max and S-band applications $(2.79 \mathrm{GHz}$ to $5.61 \mathrm{GHz})$. The $2^{\text {nd }}$ one covers the $\mathrm{C}$ and $\mathrm{X}$-band applications $(6.88 \mathrm{GHz}$ to 8.69 $\mathrm{GHz})$. The $3^{\text {rd }}$ covers the Ku-band applications $(11.43 \mathrm{GHz}$ to $14.34 \mathrm{GHz}$ ). The remaining part of the paper is divided as: Section II details the projected antenna configuration and design. Design evolution steps of try band antenna are illustrated in section IV. The results are examined in Section IV. Lastly, Section V draws the conclusions.

\section{ANTENNA DESIGN}

The design of the proposed try band antenna is based on the following equations [1].

$$
r=\frac{F}{\left\{1+\frac{2 h}{\pi \varepsilon_{r} F}\left[\ln \left(\frac{\pi F}{2 h}\right)+1.7726\right]\right\}^{1 / 2}}
$$

where $\mathrm{h}=$ height of the substrate, $\varepsilon_{\mathrm{r}}=$ dielectric constant, $F=$ $\frac{8.791 \times 10^{9}}{f_{r} \sqrt{\varepsilon_{r}}}$.

The dominant mode in circular patch is $T M_{110}^{Z}$ whose resonant frequency is:

$$
f_{r}=\frac{1.8412 C}{2 \pi a \sqrt{\varepsilon_{r}}}
$$

where $\mathrm{C}=$ velocity of wave in free space.

The effective radius 


$$
r_{e}=r\left\{1+\frac{2 h}{\pi \varepsilon_{r} r}\left[\ln \left(\frac{\pi r}{2 h}\right)+1.7726\right]\right\}^{1 / 2}
$$

The architecture of intended Medical plus shaped multiband antenna is depicted in Figure 1.

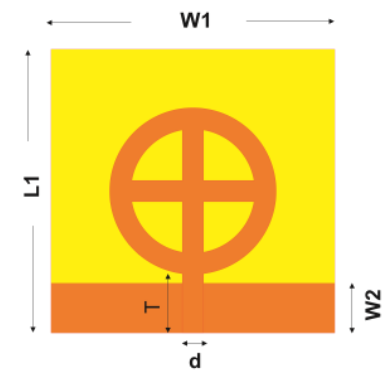

(a) Front aspect

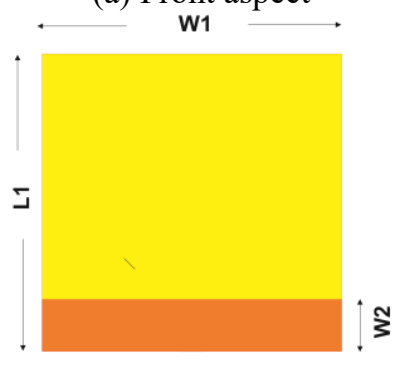

(b) Rear aspect

Figure 1. The intended antenna layout

The projected antenna consists of a medical plus shaped radiating patch on FR4-substrate with thickness $1.6 \mathrm{~mm}$, dielectric constant 4.4 and loss tangent of 0.02 . The antenna is fed with the help of $50 \mathrm{ohms}$ microstrip transmission line having a width and length of dXT. The overall antenna dimensions are $40 \times 40 \times 1.6 \mathrm{~mm}^{3}$.

The radiating patch consists of circular ring shaped copper strip with inner and outer radii 11.74 and $8.74 \mathrm{~mm}$ respectively on the substrate top. It consists of partial ground plane on the other side of the substrate with length and width 40 and $7 \mathrm{~mm}$ respectively. The partial ground plane is used to make proper impedance matching and bandwidth. Two rectangular copper strips with length and width 23 and $3 \mathrm{~mm}$ are added to circular ring to resonant antenna at multiple bands. The stored energy of the substrate decreases with the presence of circular slot and partial ground, which intern responsible for the reduction of quality factor and there by finds its path in the improvement of bandwidth. The reflections are cut down by the virtue of a microstrip line of $50 \mathrm{ohm}$. The microstrip line is employed as fed for antenna and is responsible for matching the source to antenna and reduces the reflections. Parametric analysis is used for optimization of dimensions with the help of An soft HFSS software. The Table 1 lists the optimized dimensions.

Table 1. Optimized dimensions

\begin{tabular}{ccc}
\hline S.NO & Parameters & Dimensions(mm) \\
\hline 1 & W1 & 40 \\
2 & L1 & 40 \\
3 & W2 & 7 \\
4 & $\mathrm{~T}$ & 9 \\
5 & $\mathrm{~d}$ & 3 \\
6 & $\mathrm{r} 1$ & 8.74 \\
7 & $\mathrm{r} 2$ & 11.74 \\
8 & $\mathrm{~h}$ & 1.6 \\
\hline
\end{tabular}

The intended antenna is fabricated and its photos are depicted in below Figure 2 .

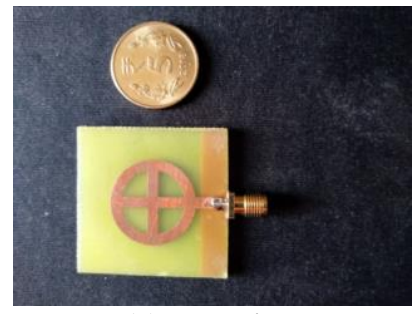

(a) Top view

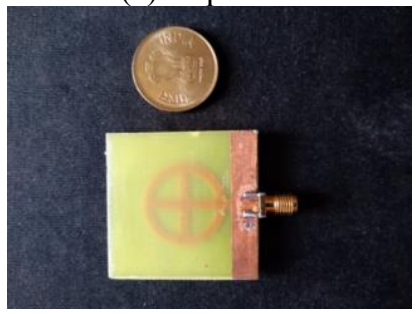

(b) Bottom view

Figure 2. Fabricated antenna

\section{DESIGN EVOLUTION STEPS}

The proposed try band antenna design evolution Steps are portrayed in Figure 3.

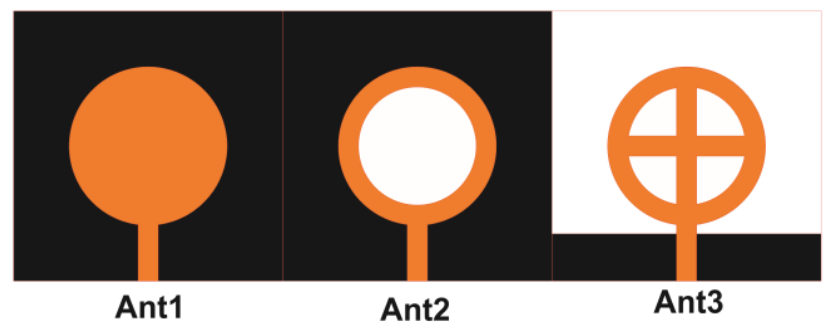

Figure 3. The evolution steps of proposed antenna

The try band proposed antenna design is carried out in three steps as follows

Step1: The antenna design starts with ant1 as shown in. The ant 1 consists of a radiating circular patch on FR4 substrate and full ground structure. The ant 1 operates at three different resonant frequencies of $6.7,9.6$ and $12.56 \mathrm{GHz}$ with the return loss less than $-10 \mathrm{~dB}$ as shown in figure. The impedance matching is good at single operating frequency. The bandwidth is very less at the operating bands.

Step 2: A circular slot of $8.74 \mathrm{~mm}$ is made to the radiating circular patch in the ant 1 to evolve ant 2 as shown in figure. The ant 2 return loss plot is illustrated in Figure 4. The ant2 operates at two different resonant frequencies of 12 and 14.7 $\mathrm{GHz}$ with the return loss less than $-10 \mathrm{~dB}$ as shown in figure. The return is not good at second frequency due to poor impedance matching.

Step 3: The ground surface is truncated and two rectangular copper strips with length and width 23 and $3 \mathrm{~mm}$ are added to circular ring in the ant 2 to evolve the ant 3 to resonant antenna at multiple bands as demonstrated in Figure 3. Here a preferable impendence matching is attained by truncating a portion of the ground surface. The ant3 operates at three resonant frequencies with return loss less than $-10 \mathrm{~dB}$ and 
exhibits wide bandwidths. The return loss of the intended ant 3 is plotted in Figure 4.

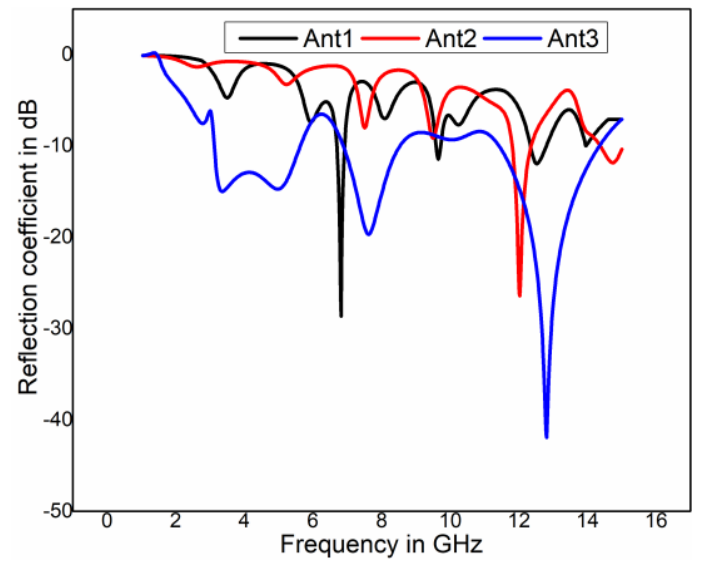

Figure 4. Return loss plot of the An1, Ant2 and Ant3

\section{SIMULATION RESULTS}

The proposed Medical plus shaped antenna has been simulated with help of the FEM based HFSS software. The same antenna is fabricated to examine its functioning at different operating frequencies. The photographs of the prototype are illustrated in Figure 2. The $\mathrm{S}_{11}$ of proposed antenna is measured by using network analyzer. In Figure 5 the simulated reflection coefficient is compared with the measured one over the three bands of the proposed antenna.

Figure 5 illustrated bellow projects operating frequencies simulated occupy the band $2.79 \mathrm{GHz}$ to $5.61 \mathrm{GHz}, 6.88 \mathrm{GHz}$ to $8.69 \mathrm{GHz}$ and $11.43 \mathrm{GHz}$ to $14.3 \mathrm{GHz}$ having return losses less than $-10 \mathrm{db}$. The operating frequencies measured holds the band of $3.12 \mathrm{GHz}$ to $5.62 \mathrm{GHz}, 6.89 \mathrm{GHz}$ to $8.52 \mathrm{GHz}$ and $11.1 \mathrm{GHz}$ to $14 \mathrm{GHz}$ baring return losses less than $-10 \mathrm{db}$. The negligible differences in the measured and simulated values are attributed to imperfection in fabrication, substrate losses, circumstances in measurement and coaxial connector influence.

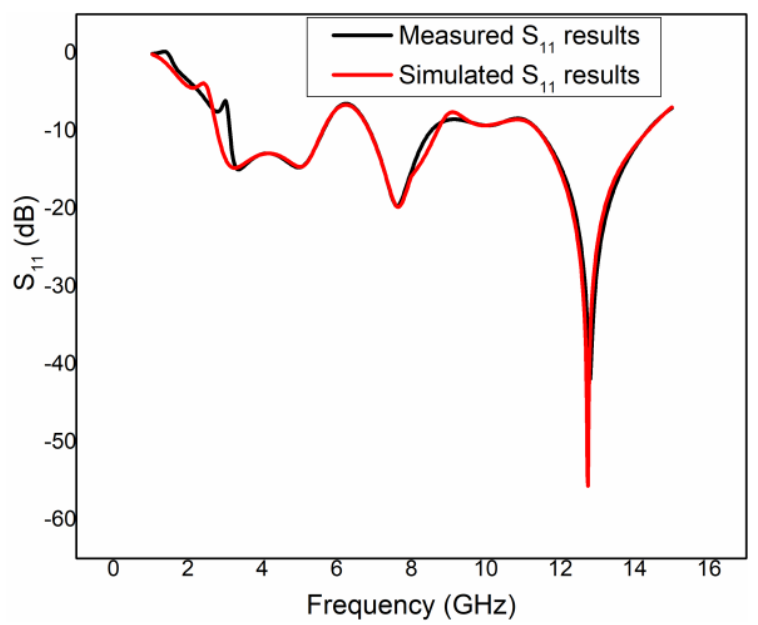

Figure 5. The plot of reflection coefficient

The simulated and measured VSWR results of the proposed try-band antenna are portrayed in below Figure 6 .

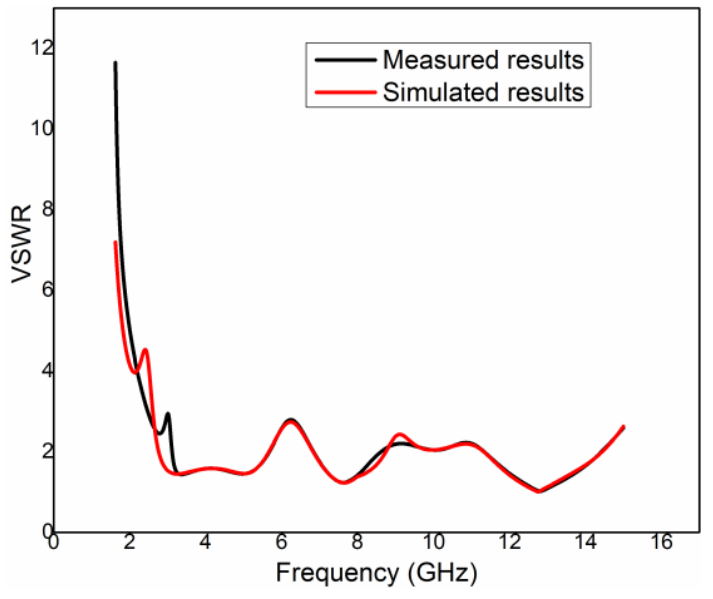

Figure 6. VSWR plot

The measured VSWR curve of the try-band antenna closely matches with that of simulated plot. The values of VSWR lie between 1 and 2 over three operating bands of the designed antenna. The try-band antenna exhibits good performance in perspective of VSWR also. The try-band antenna measurement setup is depicted in Figure 7.

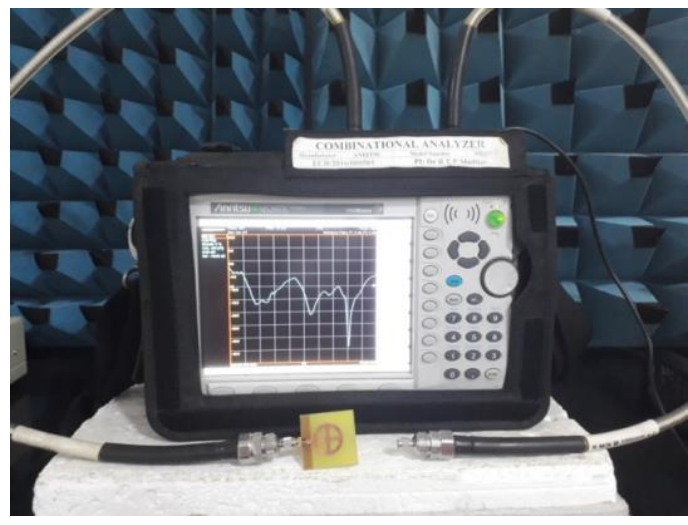

Figure 7. The photo of measurement setup of the try-band antenna

The $\mathrm{E}$ and $\mathrm{H}$-planes radiation patterns of the given antenna are simulated then measured at the various resonant frequencies of 3.2, 7.2 and $12.7 \mathrm{GHz} \mathrm{GHz}$ respectively. The corresponding patterns are portrayed in Figure 8. The radiation pattern seems omnidirectional in $\mathrm{H}$-plane and monopole in $\mathrm{E}$ plane. The proposed antenna gains are about 1.78, 5.9 and 4.4 $\mathrm{dBi}$ at 3.2, 7.2 and $12.7 \mathrm{GHz}$ respectively.

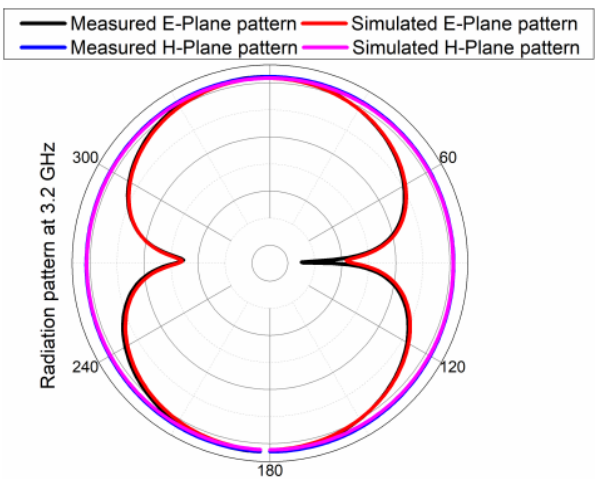

(a) 


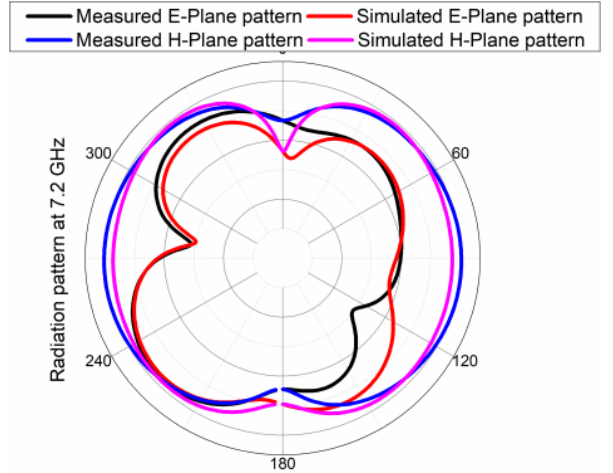

(b)

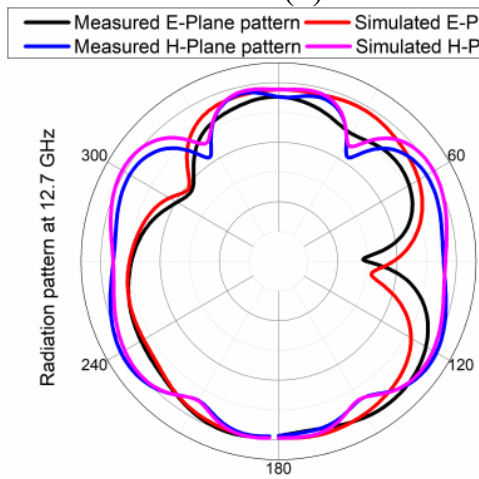

(c)

Figure 8. The projected antenna radiation pattern at 3.2, 7.2 and $12.7 \mathrm{GHz}$

\section{CONCLUSIONS}

The Medical plus shaped antenna for S, C, X and Ku Band Applications has been developed and analyzed. The tripleband antenna has a height of only $1.6 \mathrm{~mm}$. It has been demonstrated that the compact multiband antenna can cover the band of $2.79 \mathrm{GHz}$ to $5.61 \mathrm{GHz}, 6.88 \mathrm{GHz}$ to $8.69 \mathrm{GHz}$ and $11.43 \mathrm{GHz}$ to $14.3 \mathrm{GHz}$ with return loss below the $-10 \mathrm{~dB}$ line. The intended antenna exhibits good radiation pattern over the desired operating bands of the projected antenna. The measured results of the try-band antenna closely match to the simulation results. This antenna may find wide applications in the MIMO and array antennas.

\section{ACKNOWLEDGEMENT}

The authors would like to thank VEC and PBR VITS, Kavali for providing ansoft HFSS software in their R \& D Lab for design and optimization of the proposed antenna.

\section{REFERENCES}

[1] Balanis, C.A. (2016). Antenna theory: Analysis and Design. 4th ed. Hoboken (NJ): John Wiley \& Sons.

[2] Beigi, P., Nourinia, J., Zehforoosh, Y., Mohammadi, B. (2014). A compact novel CPW-fed antenna with square spiral-patch for multiband applications. Microwave and Optical Technology Letters, 57(1): 111-115. https://doi.org/10.1002/mop.28783

[3] Sharma, V., Patidar, D.K. (2017). Design and analysis of staked multiband microstrip antenna. International Journal of Advanced Research in Computer and Communication Engineering, 6(4): 74-80. https://doi.org/10.17148/IJARCCE.2017.6415

[4] Sharma, S.K., Mulchandani, J.D., Gupta, D., Chaudhary, R.K. (2015). Triple-band metamaterial-inspired antenna using FDTD technique for WLAN/WiMAX applications. International Journal of RF and Microwave ComputerAided Engineering, 25: 688-695. https://doi.org/10.1002/mmce.20907

[5] Rezvani, M., Zehforoosh, Y. (2017). Design of multiband microstrip antenna for wireless communications and ITU applications. National Academy Science Letters, 40(5): 331-334. https://doi.org/10.1007/s40009-0170574-1

[6] Hamad, E.K.I., Badr, S. (2018). Design of multiband microstrip patch antenna for WiMax, C-band and X-band applications. Aswan Engineering Journal, 1-7.

[7] Kapil, J., Ruchi, E. (2016). Multiband microstrip antenna for Bluetooth, UWB, X-Band and Ku Band applications. International Research Journal of Engineering and Technology, 3(4): 743-747.

[8] Kumari, R., Kumar, M. (2013). Microstrip patch multiband antenna for C-band, X-band and Ku-band applications, 3(3): 176-180.

[9] Prema, N., Kumar, A. (2016). Design of multiband microstrip patch antenna for C and X band. Optik International Journal for Light and Electron Optics, 127(20):

$8812-8818$. https://doi.org/10.1016/j.ijleo.2016.06.090.

[10] Khare, A., Nema, R. (2014). Triple band parasitic array antenna for $\mathrm{C}-\mathrm{X}-\mathrm{Ku}$-Band application using out-of-phase coupling approach. International Journal of Antennas and Propagation, 2014: 1-9. https://doi.org/10.1155/2014/716829

[11] Garg, R., Bhartia, P., Bahl, I., Ittipiboon, A. (2001). Microstrip antenna design handbook. Boston: Artech House. 